\title{
Klasifikasi Kematangan Buah Manggis Ekspor dan Lokal Berdasarkan Warna dan Tekstur Menggunakan Fuzzy Neural Network
}

\author{
Classifcation of Export and Local Mangosteen Maturity Based \\ on Color and Texture Based using Fuzzy Neural Network
}

\author{
RETNO NUGROHO WHIDHIASIH ${ }^{1 *}$, SUGI GURITMAN ${ }^{2}$, PRAPTO TRI SUPRIO ${ }^{2}$
}

\begin{abstract}
Abstrak
Fuzzy neural network (FNN) memiliki kemampuan untuk melakukan klasifikasi terhadap suatu pola yang berada di dalam dua kelas yang tidak dapat diklasifikasi menggunakan model klasifikasi klasik neural network (NN). Penelitian ini bertujuan mengembangkan model klasifikasi buah manggis segar secara non-destruktif dengan menggunakan FNN. FNN yang dipakai menggunakan derajat keanggotaan pada neuron output sebagai target pembelajaran. Parameter input yang digunakan adalah komponen warna hasil dari pengolahan citra yang mempunyai pengaruh terhadap tahap kematangan buah manggis dan tekstur. Hasil pemodelan FNN menjadi 2 kelas target klasifikasi (ekspor dan lokal) mendapatkan model terbaik dengan fitur penduga indeks warna merah, hijau, biru, value, $a^{*}, u^{*}, v^{*}$, dan entropi dengan 5 neuron pada lapisan tersembunyi. Perbandingan persentase akurasi model FNN dan NN ialah 90:90, dengan perbandingan kemampuan pengenalan terhadap kelas ekspor dan lokal ialah 92:100 dan 89:75.
\end{abstract}

Kata kunci: fuzzy neural network, klasifikasi, manggis, non-destructive grading, pengenalan pola

\begin{abstract}
Fuzzy neural network (FNN) has a capability to classify a pattern located within two different classes where a classical neural network (NN) is failed to do so. The objective of this research is to develop an model for non-destructive classifcation of fresh mangosteen using Fuzzy Neural Network. The fuzzy pattern classifcation is using membership degree on the output of neuron as learning target. The color component as the result of image processing which infuence the level of mangosteen's maturity is used as input parameter. The best result of FNN modeling is achieved on two classes of target classifcation (export and local) with the following predictor parameters: red, green and blue color index, value, $a^{*} u^{*}, v^{*}$ and entropy with 5 neurons hidden layer. Percentage accuracy ratio of FNN model compared to $N N$ is 90:90 respectively. Comparison of percentage capability of FNN against NN to identify the class export and local is 92:100 and 89:75 respectively.
\end{abstract}

Keyword : classifcation, fuzzy neural network, mangosteen, non-destructive grading, pattern recognition.

\section{PENDAHULUAN}

Neural network (NN) yang menggunakan algoritme pembelajaran backpropagation pada saat ini digunakan secara luas untuk klasifikasi pola. Algoritme tersebut hanya memberikan satu kelas output dari masing-masing pola input dengan asumsi bahwa batasan kelas telah didefinisikan dengan baik. Namun, dalam situasi nyata dapat terjadi batasan kelas yang overlapping, dimana suatu pola input dapat menjadi anggota lebih dari satu kelas. Untuk mengatasi keterbatasan algoritme tersebut, digunakan pendekatan klasifkasi fuzzy ke dalam algoritme backpropagation yang disebut fuzzy neural network (Pal dan Mitra 1992).

\footnotetext{
${ }^{1}$ Departemen Ilmu Komputer, Fakultas Matematika dan Ilmu Pengetahuan Alam, Institut Pertanian Bogor, Bogor 16680

${ }^{2}$ Departemen Matematika, Fakultas Matematika dan Ilmu Pengetahuan Alam, Institut Pertanian Bogor, Bogor 16680

*Penulis korespondensi: Tel/Faks: 0251-8625584; Surel: retnonw@gmail.com
} 
Fuzzy neural network (FNN) merupakan suatu model yang dilatih menggunakan jaringan syaraf, namun struktur jaringannya diinterpretasikan dengan sekelompok aturan fuzzy (Kasabow 2002). Pada FNN parameter-parameter yang dimiliki oleh neuron dan bobot-bobot penghubung yang biasanya disajikan secara numeris, dapat diganti menggunakan parameter fuzzy (Lin 1996). Adakalanya input dan bobot bernilai crisp, sedangkan output-nya bernilai fuzzy (Mashinchi dan Shamsuddin 2009). Teknik ini akan digunakan untuk mengklasifikasi tahap kematangan buah manggis.

Mutu buah manggis (Garnicia mangostana) ditentukan oleh berbagai parameter di antaranya ialah parameter tingkat kematangan berdasarkan indeks warna. Klasifikasi kematangan buah manggis hasil panen secara nondestruktif berdasarkan pada standar prosedur operasi (SPO) manggis 2004 sangat diperlukan untuk mempertahankan mutu dan meningkatkan daya saing di pasaran. Pesatnya peningkatan volume ekspor manggis dari tahun ke tahun memerlukan kepercayaan pasar dalam hal mutu (Deptan 2004).

Tingkat kematangan buah manggis dapat diklasifikasikan berdasarkan pada komponen kualitas eksternal, yaitu warna dan tekstur kulit buahnya. Warna dianggap sebagai properti fisik dasar produk pertanian dan makanan, yang berkorelasi dengan sifat kimia dan indikator panca indera kualitas produk. Warna bahkan mempunyai peranan utama dalam penilaian mutu eksternal industri makanan (Abdullah et al. 2001). Tekstur akan membedakan sifat-sifat fsik permukaan suatu benda dalam citra. Entropi, kontras, energi, dan homogenitas merupakan komponen untuk mengukur tekstur dari sebuah citra (Haralick et al. 1973).

Ruang warna yang disarankan untuk kuantifkasi makanan dengan permukaan melengkung ialah $L * a * b *$ dan hue, saturation, value (HSV). Hal ini dikarenakan intensitas cahaya dalam ruang warna $L * a * b *$ kurang terpengaruh oleh bayang-bayang pada daerah kilau pada permukaan objek, sedangkan komponen $V$ pada HSV merupakan komponen yang paling dipengaruhi oleh permukaan yang melengkung (Mendoza et al. 2006). Nilai $a * / b *$ berkorelasi baik dengan pembentukan warna buah (Palapol et al. 2009). Peningkatan ketuaan pada buah belimbing dapat ditunjukkan oleh peningkatan komponen $u^{*}$ pada $L^{*} u^{*} v^{*}$ (Irmansyah 2009).

Penelitian yang berkaitan dengan pengenalan pola telah dilakukan menggunakan FNN dan neural network (NN), di antaranya oleh Pal dan Mitra (1992), Sarkar et al. (1998), Murquia (2002), Mendoza et al. (2006), dan Sandra (2007).

Penelitian ini bertujuan untuk mengembangkan model klasifikasi tingkat kematangan buah manggis menggunakan FNN berdasarkan warna dan tekstur. Parameter yang digunakan adalah warna RGB, HSV, $L^{*} a^{*} b^{*}$, dan $L^{*} u^{*} v^{*}$ serta fitur tekstur yang meliputi fitur energi, kontras, homogenitas, dan entropi. Pemodelan yang dikembangkan merupakan pengembangan dari penelitian sebelumnya.

\section{METODE}

Data yang digunakan dalam penelitian ini adalah data sekunder berupa 125 buah citra buah manggis (Garnicia mangostana) Padang. Tahap kematangan buah pada data adalah 2 sampai 6sehingga diperoleh 25 citra buah manggis di setiap tahap kematangan dengan ukuran buah yang tidak seragam. Diameter buah manggis tidak diperhitungkan dalam pengolahan data. Warna kulit menjadi dasar klasifikasi kematangan buah manggis pada penanganan pasca panen seperti yang ditunjukan pada Tabel 1 (Deptan 2004).

Penelitian ini terbagi menjadi dua tahapan, yaitu praproses dan pemodelan FNN. Praproses dilakukan untuk mendapatkan fitur-fitur yang berpengaruh terhadap tahap kematangan buah manggis sedangkan pemodelan FNN dilakukan untuk mendapatkan model yang optimum dari jaringan.

\section{Praproses Data}

Data sampel citra buah manggis diolah menggunakan matlab R2009b untuk mendapatkan nilai RGB yang merupakan rata-rata dari keseluruhan piksel. Kemudian nilai 
Tabel 1 Tahap kematangan manggis (Deptan 2004)

Ciri
warna kulit buah kuning kehijauan, kulit buah
masih banyak mengandung getah, buah belum siap
dipetik

RGB dinormalisasi dengan cara membagi masing-masing nilai dengan bilangan 255 untuk memperoleh nilai RGB. Nilai RGB kemudian dikonversi ke dalam HSV, $L^{*} u^{*} v^{*}, L^{*} a^{*} b^{*}$, dan digunakan matriks co-occurrence dengan sudut orientasi 0 derajat untuk mendapatkan nilai fitur entropi, kontras, energi, dan homogenitas. Selanjutnya dilakukan transformasi data, yaitu pengubahan nilai-nilai fitur tersebut ke dalam rentang dari 0 sampai 1 dan membagi menjadi dua kelompok data yang saling asing, yaitu data training dan data testing. Data training diambil kurang lebih $85 \%$ di setiap tahap kematangan, yaitu berjumlah 21 data dan data yang digunakan untuk testing kurang lebih $15 \%$ di setiap tahap kematangan, yaitu berjumlah 4 . Total jumlah data training ialah $21 \times 5=105$ dan total jumlah data testing ialah $4 \times 5=20$. Hal ini dianggap cukup mengingat populasi bersifat homogen dengan mengambil tingkat presisi $20 \%$. Fitur penduga kematangan buah manggis didapatkan dan dikombinasikan menjadi empat buah model input yang akan digunakan dalam percobaan menggunakan FNN (Tabel 2).

\section{Pemodelan FNN}

Variasi FNN yang dipakai adalah input dan bobot bernilai crisp, sedangkan output bernilai fuzzy sesuai dengan model FNN tipe 5 (Mashinchi dan Shamsuddin 2009). Sebelum proses training dimulai, terlebih dahulu dilakukan pengubahan nilai target atau output menjadi pola output fuzzy. Pola output fuzzy ini digunakan sebagai nilai target pelatihan dalam jaringan. Penentuan pola output fuzzy dilakukan dengan dua tahap. Tahap pertama ialah mencari jarak 
Tabel 2 Empat model input penduga kematangan buah manggis

\begin{tabular}{|c|c|c|c|c|c|c|c|c|c|c|c|}
\hline Model & $r$ & $g$ & $B$ & $V$ & $a^{*}$ & $u^{*}$ & $v^{*}$ & Entropi & Energi & Kontras & Homogenitas \\
\hline FNN1 & & $\sqrt{ }$ & & $\sqrt{ }$ & $\sqrt{ }$ & $\sqrt{ }$ & $\sqrt{ }$ & $\sqrt{ }$ & & & \\
\hline FNN2 & $\sqrt{ }$ & $\sqrt{ }$ & $\sqrt{ }$ & $\sqrt{ }$ & $\sqrt{ }$ & $\sqrt{ }$ & $\sqrt{ }$ & $\sqrt{ }$ & & & \\
\hline FNN3 & $\sqrt{ }$ & $\sqrt{ }$ & & $\sqrt{ }$ & $\sqrt{ }$ & $\sqrt{ }$ & $\sqrt{ }$ & $\sqrt{ }$ & $\sqrt{ }$ & $\sqrt{ }$ & $\sqrt{ }$ \\
\hline FNN4 & & $\sqrt{ }$ & $\sqrt{ }$ & $\sqrt{ }$ & $\sqrt{ }$ & $\sqrt{ }$ & $\sqrt{ }$ & $\sqrt{ }$ & $\sqrt{ }$ & $\sqrt{ }$ & $\sqrt{ }$ \\
\hline
\end{tabular}

Keterangan:

FNN: fuzzy neural network

FNN1, FNN2, FNN3, FNN4: model input FNN dengan kombinasi nilai ciri yang berbeda

$r$ : red, g: green, $b$ : blue, $V$ : value,

$a^{*}$ : informasi komponen kromatik warna hijau sampai merah,

$u^{*}$ : kuat warna pada sumbu merah sampai hijau,

$v^{*}$ : kuat warna pada sumbu kuning sampai biru.

terbobot pola pelatihan terhadap kelas target yang didefinisikan dengan persamaan (Sarkar et al. 1998).

$$
z_{i k}=\sqrt{\sum_{j=1}^{n}\left[\frac{x_{i j}-m_{k j}}{v_{k j}}\right]^{2}} ; k=1, \cdots, p
$$

dengan $m_{k}$ dan $v_{k}$ adalah mean dan deviasi standar dari kelas ke- $k, x_{i j}$ adalah nilai komponen ke-j dari pola ke- $i$. Tahap kedua ialah menghitung derajat keanggotaan pola pelatihan berdasarkan hasil perhitungan jarak terbobot dengan persamaan (Sarkar et al. 1998).

$$
\mu_{k}\left(x_{i}\right)=\frac{1}{1+\left(\frac{z_{i k}}{f_{d}}\right)^{f_{e}}} ; k=1, \cdots, p
$$

dengan $f_{d}$ dan $f_{e}$ adalah konstanta yang akan mengendalikan tingkat kekaburan pada himpunan keanggotaan kelas tersebut. Dari persamaan ini diperoleh $p$ vector derajat keanggotaan:

$$
\left[\mu_{1}\left(x_{1}\right), \mu_{2}\left(x_{2}\right), \cdots, \mu_{p}\left(x_{p}\right)\right] \text {. }
$$

Struktur FNN yang digunakan dalam pelatihan untuk mendapatkan model jaringan FNN yang optimum dalam penentuan tahap kematangan manggis pada penelitian ini disajikan pada Tabel 3. Pengambilan keputusan dilakukan dengan mengambil nilai yang terbesar dari keluaran FNN yang berupa vektor kolom, tempat kolom nilai terbesar tersebut menunjukkan posisi kelas. Fungsi kinerja yang digunakan ialah mean square error (MSE) yang didapatkan dari nilai rata-rata kuadrat error yang terjadi antara output jaringan dan target output. Ketepatan klasifikasi hasil prediksi menggunakan FNN dinyatakan menggunakan akurasi yang didefinisikan sebagai berikut:

$$
\text { akurasi }=\frac{\text { jumlah prediksi yang benar }}{\text { total banyaknya prediksi }} \times 100
$$

\section{HASIL DAN PEMBAHASAN}

Classifier yang digunakan ialah FNN. FNN telah digunakan dalam masalah pengenalan dan klasifikasi dengan hasil yang bagus (Mohamed dan Nyongesa 2002). Data training menggunakan parameter input dan bobot bernilai crisp, sedangkan output-nya bernilai fuzzy (Pal dan Mitra 1992, Lin 1996) mengikuti salah satu tipe FNN (Mashinchi dan Shamsuddin 2009). Pola output fuzzy merupakan target output pelatihan yang terdiri dari kelas ekspor dan kelas lokal. Pola output fuzzy digunakan untuk mengubah batasan kelas secara tegas ke dalam batasan bersifat fuzzy (Sarkar et al. 1998) berupa nilai-nilai dengan range antara 0 dan 1 
bergantung pada derajat keanggotaan dari pola input terhadap masing-masing kelas seperti pada Gambar 1.

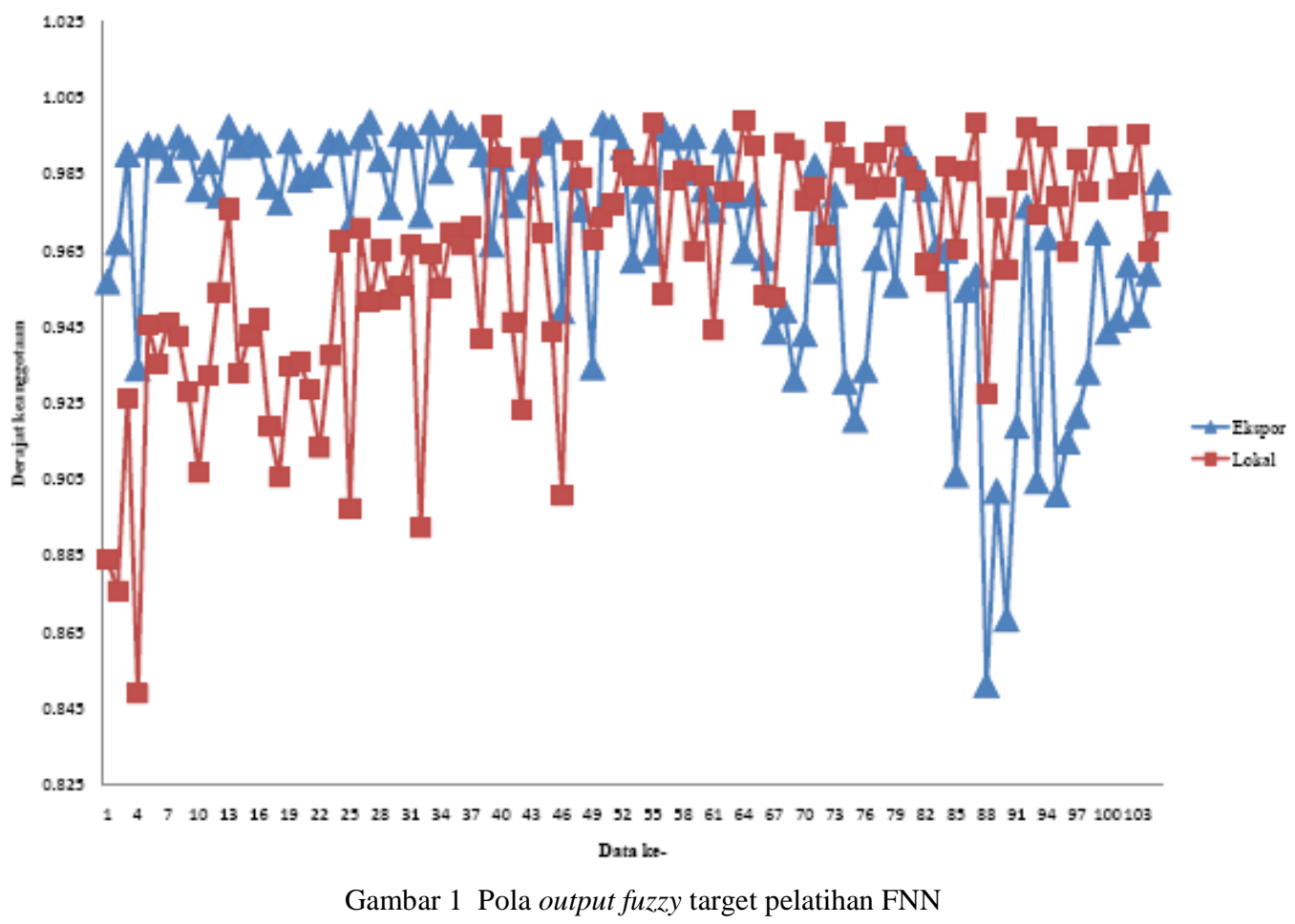

Nilai-nilai tersebut menunjukkan derajat keanggotaan tiap pola input terhadap tiap kelas kematangan, yaitu kelas ekpor dan kelas lokal. Derajat keanggotaan mempunyai nilai yang sangat dekat satu sama lain, hal ini menunjukkan bahwa suatu pola dimungkinkan menjadi anggota dari 1 kelas atau lebih, sehingga terdapat ambiguitas yang tinggi dalam penentuan kelas kematangan buah manggis jika dilakukan menggunakan klasifikasi klasik.

Proses training pada percobaan FNN ini dilakukan dengan struktur sesuai pada Tabel 3 yaitu menggunakan multilayer perceptron (MLP) (Pal dan Mitra 1992). Unjuk kerja pembelajaran dalam percobaan ini diukur menggunakan MSE, berbeda dengan (Pal dan Mitra 1992) yang menggunakan MSE dan cross entropy untuk mendapatkan nilai yang terus menurun dan mencapai minimum lokal. Model dicoba dengan menggunakan jumlah layar tersembunyi (hidden neuron) yang berbeda (Tabel 3) pada tiap jumlah neuron input yang berbeda (Tabel 2) yang merupakan kombinasi fitur penduga tahap kematangan manggis. Pada proses training digunakan data training sebanyak $85 \%$ dari data set. Parameter $f_{d}$ dan $f_{e}$ dalam percobaan ini menggunakan $f_{d}=1$ dan $f_{e}=1$ (Sarkar et al. 1998). Masing-masing variasi model input penduga tahap kematangan manggis dan hidden neuron dicoba sebanyak 25 kali ulangan, sehingga total percobaan dilakukan sebanyak 600 kali.

Hasil percobaan menunjukkan bahwa perubahan kombinasi parameter input penduga tahap kematangan manggis dan perubahan jumlah neuron lapisan tersembunyi cukup berpengaruh dalam mendapatkan pola pengenalan. Dalam penelitian ini digunakan persentase untuk mengukur tingkat pengenalan dari data training dan data testing. Hasil pengenalan terbaik yang didapatkan dari percobaan FNN dalam mengklasifikasi 20 citra buah manggis (data testing) menjadi kelas ekspor dan kelas lokal menggunakan empat model input penduga tahap kematangan manggis ialah input model FNN2 dengan 5 neuron pada lapisan tersembunyi yang diperoleh mean square error (MSE) sebesar 0,000106.

Untuk mengetahui efektivitas klasifikasi fuzzy dalam mengklasifikasi tahap kematangan buah manggis menggunakan MLP FNN dalam penelitian ini dilakukan juga percobaan menggunakan klasifikasi klasik MLP NN seperti yang dilakukan Sandra 2007. Percobaan ini dilakukan hanya menggunakan model input penduga kematangan manggis hasil training 
terbaik FNN, yaitu FNN2 dengan struktur jaringan, variasi jumlah neuron dan jumlah ulangan percobaan yang sama, sehingga total percobaan dilakukan sebanyak 150 kali.

Hasil terbaik yang didapatkan dari percobaan NN dalam mengklasifikasi 20 citra buah manggis (data testing) menjadi kelas ekspor dan kelas lokal adalah percobaan menggunakan 15 neuron pada lapisan tersembunyi yang diperoleh MSE sebesar 0,102.

Perbedaan hasil klasifikasi menggunakan klasifikasi fuzzy dan klasifikasi klasik disajikan dalam matriks confussion pada Tabel 4. Terdapat perbedaan hasil prediksi output dari FNN menggunakan target output pelatihan berupa derajat keanggotaan dengan prediksi output dari NN menggunakan target pelatihan berupa bilangan crisp.

Tabel 4 Matriks confussion hasil klasifikasi FNN dan NN

\begin{tabular}{lcccc}
\hline & Prediksi & FNN & Prediksi & NN \\
\hline & Ekspor & Lokal & Ekspor & Lokal \\
\hline Target Ekspor & 11 & 1 & 12 & 0 \\
Target Lokal & 1 & 7 & 2 & 6 \\
\hline Keterangan: \\
FNN: fuzzy neural network, NN: neural network \\
Target ekspor, target lokal: data yang digunakan untuktesting \\
Prediksi: hasil output dari proses testing
\end{tabular}

Nilai-nilai ambigu yang tidak dapat diklasifikasi dengan baik menggunakan klasifikasi crisp (NN) dapat diselesaikan menggunakan klasifikasi fuzzy menggunakan FNN, namun rata-rata akurasi yang dihasilkan masih tetap sama. Klasifikasi fuzzy untuk mengklasifikasi tahap kematangan buah manggis akan jauh lebih bermakna jika digunakan untuk klasifikasi dengan jumlah target output yang semakin besar karena nilai-nilai yang ambigu akan menjadi lebih banyak, misalnya dengan target output mentah, ekspor dan lokal atau enam tahap kematangan buah manggis.

Hasil klasifikasi tahap kematangan buah manggis menggunakan FNN dengan fitur penduga tahap kematangan buah manggis $a^{*}$ dalam ruang warna CIELab dan nilai $V$ dalam ruang warna HSV (Mendoza et al. 2006), $u^{*}$ dan $v^{*}$ pada ruang warna CIELuv (Irmansyah 2009), dan entropi (Haralick et al. 1973) menghasilkan akurasi 90\% dengan kelas manggis ekspor yang terklasifikasi dengan benar sejumlah 11 dari 12 data dan kelas manggis lokal yang terklasifikasi dengan benar sejumlah 7 dari 8 data.

Kesalahan yang terjadi dapat dikurangi dengan mengambil fitur-fitur penduga tahap kematangan buah manggis dari citra buah manggis dengan resolusi yang lebih tinggi (Murquia 2002), melibatkan ukuran diameter dari buah manggis yang berukuran seragam serta menggunakan rata-rata dari keempat sudut orientasi matrik co-occurrence yang digunakan untuk mengambil nilai tekstur, sehingga akan didapatkan nilai-nilai fitur yang lebih mencirikan tahap kematangan buah manggis.

\section{SIMPULAN}

Kombinasi parameter input penduga tahap kematangan manggis dan perubahan jumlah neuron lapisan tersembunyi berpengaruh untuk mendapatkan pola pengenalan. Meskipun model FNN dan NN menghasilkan akurasi pengenalan yang sama, namun model FNN dapat mengenali tiap kelas klasifikasi dengan lebih halus.

Hal ini menunjukkan kelebihan klasifikasi fuzzy dibandingkan dengan klasifikasi klasik.Model FNN terbaik untuk mengklasifikasi tahap kematangan buah manggis diperoleh dengan 8 parameter penduga yaitu red, green, blue, value, $a^{*}, u^{*}, v^{*}$, dan entropi serta 5 neuron pada lapisan tersembunyi menghasilkan akurasi $90 \%$.Model klasifikasi tahap kematangan buah manggis menggunakan FNN layak digunakan sebagai model alternatif dalam klasifikasi tahap kematangan buah manggis berdasarkan warna dan tekstur. 


\section{DAFTAR PUSTAKA}

Abdullah MZ, Guan LC, Karim AA. 2001. The application of computer vision system and tomographic radar imaging for asessing phisical properties of food. Food Engine. 61(1):125-135. dx.doi.org/10.1016/S0260-8774(03)00194-8.

Departemen Pertanian. 2004. Standar Prosedur Operasi. Jakarta (ID): Direktorat Tanaman Buah Departemen Pertanian.

Haralick RM, Shanmugam K, Dinstein I. 1973. Textural features for image classifcation. IEEE Trans on Syst, Man and Cybernetics. 3(6):610-621.

Irmansyah. 2009. Pemutuan belimbing berdasarkan warna dan rasa dengan pengolahan citra dan logika fuzzy [disertasi]. Bogor (ID): Institut Pertanian Bogor.

Kasabow N. 2002. Evolving Neuro Fuzzy Inference System. London (UK): Prentice Hall.

Lin CT, George L. 1996. Neural Fuzzy System. London (UK): Prentice Hall.

Mashinchi MH, Shamsuddin SH. 2009. Three-term fuzzy back-propagation. Foundations of Computer Intelligent. 1:143-158.

Mendoza F, Dejmek P, Aquilera JM. 2006. Calibrated color measurement of agricultural foods using image analysis. Postharv Bio and Tech. 41(3): 285-295. 10.1016/j.postharvbio.2006.04.004.

Mohamed S, Nyongesa H. 2002. Automatic fngerprint classifcation system using fuzzy neural techniques. Fuzz-IEEE. 1: 358-362. 10.1109/FUZZ.2002.1005016.

Murquia MI. 2002. A fuzzy neural network approach for document region classifcation using human visual perception features. Comp y Sist. 6(2): 083-093.

Pal SK, Mitra S. 1992. Multilayer perceptron, fuzzy sets and classifcation. IEEE Trans On Neural Networks. 3(5): 683-697. 10.1109/72.159058.

Palapol Y, Ketsa S, Stevenson D, Cooney JM, Allan AC, Ferguson IB. 2009. Colour development and quality of mangosteen (Garcinia Mangostana L.) fruit during ripening and after harvest. Posthar Bio and Tech. 51(3): 349-353. dx.doi.org/10.1016/j.postharvbio.2008.08.003.

Sandra. 2007. Pengembangan pemutuan buah manggis untuk eksport secara non destruktif dengan jaringan syaraf tiruan [disertasi]. Bogor (ID): Institut Pertanian Bogor.

Sarkar M, Yegnanarayana B, Khemani D. 1998. Backpropagation learning algorithms for classifcation with fuzzy mean square error. Pattern Recog Letters. 19: 43-51. 